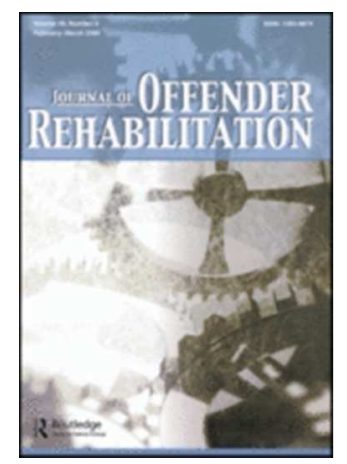

\title{
Exploring alternative terrain in the rehabilitation and treatment of offenders: findings from a prison-based music project
}

\begin{tabular}{|r|l|}
\hline Journal: & Journal of Offender Rehabilitation \\
\hline Manuscript ID & WJOR-2015-0546.R2 \\
\hline Manuscript Type: & Original Article \\
\hline Keywords: & $\begin{array}{l}\text { offender rehabilitation, principles of effective intervention, prison-based } \\
\text { programs, program evaluation, qualitative research }\end{array}$ \\
\hline \multicolumn{2}{|l}{} \\
\hline
\end{tabular}

SCHOLARONE ${ }^{m}$

Manuscripts

URL: http://mc.manuscriptcentral.com/wjor Email: journal@uic.edu 
Title: Exploring alternative terrain in the rehabilitation and treatment of offenders: findings from a prison-based music project

\title{
Key Words:
}

Arts in prison; rehabilitation; treatment; offender's voices;

\section{Running header:}

Arts based contribution to rehabilitation

\begin{abstract}
:
The arts in prison settings have provided an alternative or complimentary component to rehabilitation. Despite increased interest, studies capturing the voice of offenders participating in projects and the long-term impact are limited. Data from semi-structured interviews with eighteen men, who had taken part in a music-based project while incarcerated, including one group of five participants who were tracked for eighteen months with supplemented data from correctional staff and official documentation is presented. Participants of the art-based projects comment on changes they believe to have derived from participating in the project, particularly relating to emotions, self-esteem, self-confidence, communication and social skills. An ex-offender sample of participants reported that participation in art projects provide experiences that promote beneficial skills that have been useful for post prison life.
\end{abstract}




\section{Introduction}

Arts based projects have a long and complex history of work with offenders (Cox \& Gelsthorpe, 2012) and anecdotal evidence suggests that arts in prison programmes can have a significant effect on offenders who take part in them - on their well-being, self-esteem, behaviour, treatment engagement, and engagement with further learning. Research on the arts in criminal justice has begun to provide an evidence base, suggesting arts projects can and do have a positive impact on offenders - for example, on their anger and aggression (Blacker, Watson, \& Beech, 2008), and potentially on helping offenders work towards non-offending futures (Bilby, Caulfield, \& Ridley, 2013; Cox \& Gelsthorpe, 2008). However, there remains a paucity of research on the role of the arts in criminal justice and in particular few studies have investigated the longer-term impact of arts programmes on offenders after participating in a project.

\section{The role of the arts}

While prison interventions typically focus on reducing reoffending, there is a growing appreciation for the role of non-traditional programmes and their impact, particularly in engaging prisoners in more formal treatment and education programmes. One such area of interest is the growing optimism about the role of the arts. Parkes and Bilby (2010) have charted how arts and spiritual interventions with prisoners, as opposed to interventions based on psychology, training or education can map an "alternative terrain to traditional concepts of rehabilitation and treatment", and suggest that we should have the courage to allow prisoners to "create" (Parkes \& Bilby, 2010: 106). At a most basic level, given the varying needs of those in prison, the range of inputs is likely to be required to address the variety effectively. In the United Kingdom - where the research presented in this paper was conducted - the criminal justice governing bodies believe that learning opportunities need to address 
responsiveness and diversity issues (Ministry of Justice, 2013; National Offender

Management Services, 2012) and there has been some recognition of 'the important role that the arts, collectively, can play in the rehabilitation process' (Ministry of Justice, 2010: 19). Voluntary groups are praised for their ability to be flexible and responsive to the needs of individual offenders (Ministry of Justice, 2008) and arts based programmes are typically run by such voluntary organisations. Prisoners with low literacy levels can be reluctant to engage with the 'basic skills' programmes offered in prisons. These kinds of formalised educational courses can seem similar to the education they were reluctant to engage with at school. Furthermore, many formal rehabilitation programmes are inaccessible for offenders with a low IQ (Prison Reform Trust, 2013). For these individuals, arts-based programmes that show them they can achieve may act as the first step towards further, more formal, education and training (Wilson \& Logan, 2006). It is suggested that up to $80 \%$ of prisoners in many Western countries have poor literacy (Scottish Prison Service, 2012) and that educational background is statistically associated with risk of re-offending. Owers (2008) and Reuss (1999) argue that creative and innovative ideas are needed in order to help prisoners benefit from the wider impact of education and also to engage them in such processes in the first instance, given that many prisoners are "failed learners".

Aside from considering the potential of the arts in engaging offenders, it is important to also consider the humanising effect on individuals taking part in arts programmes. Prison incarcerates offenders but also aims to rehabilitate and provide purposeful activity (HM Prison Service, 2015). Engaging with the arts in prison environments has been described by Allen, Shaw, and Hall (2004) as a "humanising experience", which enables prisoners to acquire educational achievements and also improves self-confidence, social skills and personal development. Increasing offenders' self-esteem, communication skills, and self- 
worth have value in their own right and arts programmes have been shown to tackle these areas (Cox \& Gelsthorpe, 2008; Miles \& Clarke, 2006).

Despite increased interest in the role of the arts in offender rehabilitation, Albertson (2015) contends that the literature has omitted to include the experience of the experts themselves in the form of the testimony of the prisoners accessing these projects. Bilby et al. (2013) provide a recent exception to this, including a cross-section of adult and juvenile, male and female offenders involved in a variety of arts-based programmes. While Bilby et al. reported a range of positive outcomes for the offenders in their sample, they were unable to investigate whether any of their findings were sustained in the longer term.

\section{Good Vibrations}

Good Vibrations presents an example of a charity providing a service beyond the remit of 'traditional' education and training providers, using a unique form of music training and group work. Good Vibrations uses gamelan percussion music from Indonesia that has been identified as suitable for community or group settings; it has an informal and inclusive approach; and includes a variety of instruments that can be played without any prior musical training or knowledge of musical notation (Eastburn, 2003). It is a particularly communal form of music-making where participants are compelled to work together (Henley, 2009). Good Vibrations projects typically run over one week for around fifteen-to-twenty offenders on average. As well as learning how to play traditional pieces of gamelan music, participants create their own compositions as a group. They also learn about Indonesian culture and associated art forms (e.g. shadow puppetry, Javanese dance). At the end of the week, offenders perform a concert to which staff, peers, family members and others are invited. A number of small-scale reviews of Good Vibrations have been carried out (Digard, Grafin von Sponeck, \& Liebling 2007; Eastburn, 2003; Wilson \& Logan, 2006). Digard et al., 
(2007), suggested there were positive impacts on those who participated in a Good Vibrations project, including increased insight and reflection, and also stronger cohesion in groups of prisoners.

Research by Wilson and Logan (2006) suggests that taking part in the gamelan sessions and successfully completing the whole week empowered prisoners to seek further education and training opportunities. This was attributed to the 'uniqueness' of Good Vibrations and the inclusive approach of the tutors, which enabled prisoners to develop social skills to work together and also discuss wider issues during the sessions. Wilson and Logan also suggested that Good Vibrations projects removed the barrier of intimidation towards engaging in education for many prisoners. Prisoners' self-esteem and confidence were also reportedly increased, to the extent that many talked of not just wanting to change but also feeling they had the capacity and ability to do so (Wilson \& Logan, 2006).

The findings highlighted above suggest that Good Vibrations projects may have a positive impact on specific groups, but, given the small-scale and short-term focus of these reports, also draw attention to the need for further research to investigate how far these findings can be generalised and whether any impact is sustained long-term in the lives of offenders.

\section{Research objectives and aims}

In light of recommendations that effective research into the arts should track participants over time (Miles \& Clarke, 2006), and against the background of previous research, the overall objective of this study was:

- To consider and capture the experience of taking part in the Good Vibrations project over an eighteen month period through self-reflections (in their own words). In particular the aims were; 
- To capture participants' reflections particularly with respect to changes in attitudes, emotions and behaviour

- To consider official documentation and reports from prison staff to triangulate.

- To track participants' engagement with further learning, education and selfdevelopment.

- To compare the findings from the original sample of participants to other groups of project participants.

- To follow a sample of male participants from a variety of prisons as they move out into the community.

\section{Method \\ Design \\ The research was conducted in three stages:}

- Stage One involved evaluating a new cohort of recent project participants, in order to increase the validity of the findings of previous research.

- Stage Two considered the long-term impact of the Good Vibrations project to offenders who had taken part in previous research as they progressed through the prison system.

- Stage Three reviewed the effects of the project on participants from a variety of prisons as they moved out into the community. 


\section{Participants}

Participants were recruited from two Category B English Prisons that had recently hosted a Good Vibrations Project, along with a sample of ex-offenders who had left prison and were living in the community. Category B prisons house offenders that do not require maximum security but who still pose a moderate amount of risk and therefore require fairly high security. Table 1 details the research process in stages along with the number of participants available and recruited.

\section{** Insert Table 1 about here**}

- Inclusion and exclusion

For the purposes of this research, females, young males, and those who had been patients in secure units were not contacted as the aim at this stage was to begin to build upon the existing evidence on the impact of the project with men in prison. In all, collecting data on male participants in this way begins to review on a broader scale the effects of participating in a Good Vibrations project on male offenders, and it is therefore possible to suggest that any impact of the project on these ex-offenders may also in the future be experienced by the current offenders who have taken part in this research.

- Recruiting ex-offenders

The research team were aware from the start that contacting ex-offenders is notoriously fraught with difficulties (Jupp et al., 2006). However, with the assistance of Good Vibrations a database of thirty-three men who fit the project criteria was compiled. Of these thirty-three, we were able to interview five men. Many of the phone numbers and email addresses were incorrect, some of the men had not been released as early as they had hoped and so were still in prison, and despite weeks of trying, we could not get an answer from some of the numbers. 
The five men whom we were able to gain contact with were very helpful and appeared eager to be involved in the research. Four face-to-face interviews and one telephone interview were conducted. It should be noted that the findings below are based on self-report and it has not been possible to corroborate the facts, other than the information from Good Vibrations confirms the prison they were in at the time of taking part in a project.

\section{Materials}

\section{- Semi-structured interviews}

The interview schedules were based on those used in previous research (Wilson, Caulfield, \& Atherton, 2009) and amended for use at the different stages of this research. Subsequent interviews were conducted 6 months and 18 months after completing the Good vibrations project. Participants were interviewed at length and were asked: to describe their experiences of the project; what they gained from it; and specifically to focus on their experiences and behaviour after the project. The duration of the interviews were generally between one hour to one hour and a half. In order to help enhance each participant's memory of the Good Vibrations project, the researcher asked them to talk through the week explaining why they took part, how they found the course, the involvement of staff in the course and so on. Participants were also asked to explain various aspects of their behaviour, attitudes, and activities in the months since completing the project. Participation was voluntary and therefore no compensation was given for taking part. The participant consent form detailed that participation was entirely voluntary and that those who did choose to participate were "free to withdraw at any time without giving any reason, without my parole, standard of care, rights or privileges being affected".

- Informal interviews with prison staff 
Interviews were conducted with prison staff. These interviews were 'informal' as for pragmatic reasons they were conducted on an 'ad-hoc' basis rather than scheduled basis to fit around the individual's diary for that day. The purpose of these interviews were to assess the quality of the information gained from interviews with the prisoners, and to provide a modest form of internal data triangulation, prison officers in regular contact with the participants were interviewed about their views generally about these individual men and specifically about their attitudes, behaviour, and activities over the past six and twelve months. Given the complexities of prison-based research, it was not possible to interview the same prison officers at the six and eighteen month follow-up. In total eight prison staff participated in the research interviews: two at the prison involved for stage two only; six at the original prison (one wing officer interviewed for each wing where participants resided).

All interviews were conducted on a one-to-one basis by one of the researchers either in the participating prisons or at a suitable public place in the community. Interviews were digitally recorded and transcribed.

\section{- Offender Assessment System (OASys) and adjudication reports}

The research team was granted access to each participant's OASys ${ }^{\mathrm{i}}$ data and adjudication reports. The prison research co-ordinator and each individual participant agreed to this. The OASys data was collected to provide background and risk-level data on participants. Any breaking of prison rules is typically dealt with by issuing adjudications in prison, therefore adjudication data were collected to monitor numbers of adjudications before and after taking part in a Good Vibrations project.

\section{Ethics}


This project gained ethical approval by Birmingham City University’s Psychology Research Committee

\section{Data analysis}

The lead researcher produced the transcript of the interviews and conducted the data analysis. A thematic analysis approach was taken, beginning with an in-depth coding process involving the entire body of interview data (Caulfield \& Hill, 2014). The coding was initially led by themes identified through the literature, noted by the researcher during interviews, when listening to recordings, in the transcription process, and reading transcripts. These themes acted as a basis for coding, supplemented by new themes emerging during the coding process. Armstrong, Gosling, Weinman and Martaeu (1997) support that the thematic analysis process is robust and a singular researcher analysis produces meaningful and reliable results, however, any differentiation that is found usually relates to the packaging of the results. That said, the overall packaging of results has been accomplished through collaboration between the authors.

\section{Research Findings}

The results below are presented by stage, under the thematic headings identified from the data.

\section{Stage One - Recent Good Vibrations participants}

The findings presented below add support to previous research on the impact of Good Vibrations and suggest that the findings with the initial sample are not unique to that group of participants. All participants reported finding the experience enjoyable and beneficial. They were extremely positive about the Good Vibrations staff and described the week in a vivid 
amount of detail. There are a number of areas where the effects of the project were felt deeply. These are discussed below.

\section{- Anger reduction and improved relaxation}

Anger and aggression were over-riding issues for two of the men interviewed in this stage of the research. Both reported that they expected to become involved in some form of conflict with either group members and/or Good Vibrations staff throughout the week as this would be usual for them. However, this did not happen and this surprised these men.

"I would recommend the project, especially for people with emotional issues. Not just for anger, you've got self-harmers too. I was going through a bad patch, where I was getting those angry thoughts and self-harm thoughts, and for that week I just didn't get none of it. I was just...it was chilled."

Furthermore, even those men with no reported anger or aggression problems explained how relaxing the project was and how this sense of calm helped them deal with prison life during that week but also in the days that followed.

"It had a bigger impact initially, and then I've had to incorporate that impact into daily life on the wing...It's definitely had an impact on daily life, on how I try to chill. Like now I try to take an hour a day a to relax..."

Participants stated that they did not expect to experience any positive mood changes, but they did and these were significant. Two men reported that it allowed them to channel calm 
feelings instead of angry ones. All of the men described how they have continued to listen to the $\mathrm{CD}$ they were given and they use this to relax:

"My Gamelan CD has had more use than any other CD in my cell. And it's not really my sort of thing, but if you're stressed you just sort of chill."

- Communication and social skills

One of the most significant findings here was the increase in communication and social skills reported by participants. Participants reported that the project had enhanced their listening skills, allowed the more introverted participants the space to find their voice in the group, and also brought the men together as a group. Overall the participants felt the group had worked well together and bonded. One participant commented that he would be able to apply these group-work skills to life outside prison in dealing with people he might otherwise not get on with - 'you put your differences aside to get the job done.' The men felt the praise they were given after the concert and the huge sense of pride and achievement increased their confidence and self-esteem a great deal.

Interestingly, it was one of the men who had previously taken part in this research and who had one of the most difficult life histories of anyone we spoke to that expressed how Good Vibrations had helped him learn to trust people. This was echoed here by another participant with a difficult history.

\section{- Level of impact}

All four participants explained the sense of freedom the project had given them - 'like being normal again'. For three of the four men here, the project highlighted the positive benefits of using their time constructively and doing something meaningful. For one of the men here, 
and one of the men interviewed at Stage One, the project appeared to have had little effect beyond that of a week's calming distraction from prison life and a relatively fulfilling experience. However, these men reported having already developed the skills others have gained from the project. Despite this both saw that the project can impact on other people in a much more significant way. That the project was a good experience for these men is a positive finding, however others have reported that the project was the beginning of longlasting positive changes. As one participant put it "I've gained so much from this, but now it's on me to build on these skills".

\section{- Staff reports}

Staff confirmed reports from the men. The two men with anger and aggression issues were described as such by staff, but staff also noted that during the project these men had been much calmer and less argumentative. The least confident of the participants was reported to typically have problems taking praise or criticism, but was dealing with this much better. In general staff discussed the project in terms of the positive impact it has on participants at the time and of how much enjoyment they got out of it, but they did not report feeling it had any longer-term impact on participants. When probed some staff saw that for a few of the men who have taken part previously it helped with their confidence issues.

\section{Stage Two - Tracking participants over eighteen months}

It is interesting to note that all participants who were interviewed highlighted the impact the project had made upon them, over and above the other activities within the prison.

Participants described initially feeling apprehensive about the project, particularly about the idea of performing a concert at the end of the week. However, they quickly felt at ease in the 
group and experienced a great sense of achievement after performing the concert. All participants talked positively about their experiences of the project and overall it seems that for all but one of the participants they were able to use this experience as the building blocks for further personal development.

- Confidence, communication, and social skills

Perhaps one of the most significant findings to emerge from this research is the general improvement in social network and communication skills reported by participants and observed by prison staff. These improvements are sustained for up to eighteen months, at least in the prison setting. Participants reported an increased empathy and bond with other participants and staff, which translated into a willingness to communicate with a wider variety of fellow prisoners.

\footnotetext{
"It brings people together who you would never ever talk to...brought everyone together, we had mutual ground."
}

Participants spoke of the importance of developing skills beyond that of learning to play instruments, namely listening and communication skills, which with hindsight, many reported they never really had before. Of particular note is how the project altered participants' perception of others, making them feel more comfortable around people they had not met before. At the eighteen month follow-up, six of the men had maintained and developed close friendships with others from the group, and through this developed new friendships with other men from their friend's wings. Some of these men had stated that before the project they would not have spoken to some of those that they now held close friendships with specifically because they were from 'the sex-offenders wing'. 
For security reasons prison staff were required to be present during the project. The impact of this on prisoners' perceptions and relationships with staff was an important outcome of the Good Vibrations project as afterwards they felt they had something in common. This enabled a relationship of trust to develop between staff and prisoners, as prisoners began to see staff as 'human' rather than 'just a uniform':

\begin{abstract}
"Previously, I despised staff, see them as authority, never really got into talking to them but now am on first name basis, interacting a lot more because [during the project] I didn't just see them as staff I saw them as people. That was a big eye opener."
\end{abstract}

Prisoners also reported that relationships with other staff who had not been involved in the project improved. Seemingly once prisoners begin to see past the uniform, they are able to judge all prison staff as individuals. At the six month and eighteen month follow-up both participants and staff reported that these improvements in relations had been sustained.

- Skills development, training and education

All participants expressed a great degree of pride and sense of achievement at having completed the course, and in particular having had the courage to take part in the concert in front of fellow prisoners and staff on the final day. In the past many participants had started other courses or programmes that for various reasons they had not completed. Completion and presenting their skills gave participants 'a sense of achievement and wellbeing'. As a result of this sense of achievement, six months after completing the project participants stated they were more confident to learn other things and more open to the idea of developing other skills. 
For some, this sense of empowerment had encouraged them to consider other courses and they had begun to be proactive at learning other skills. This was demonstrated by one participant who contacted the county library to get more information on Indonesian culture. Others had taken part in and made active moves towards educational courses offered within the prison.

Participants compared the project to a range of other courses, both educational and artsbased. Some reported they felt other courses were inflexible and didn't allow participants to have a voice and express their opinions. The personal gains from Good Vibrations were cited as being as important as learning practical skills or educational attainment, but also served to highlight that learning had taken place in a highly enjoyable and rewarding way. This enjoyment, combined with the sense of achievement, encouraged the moves towards further learning, training and education mentioned above. One participant succinctly described the Good Vibrations project as 'a stepping-stone to other education'. At the eighteen month follow-up three of the men who had previously been reluctant to engage with education were now working towards recognised qualifications. The reasons given by the men for this change are twofold: increased personal confidence allowed them to push their boundaries even further; and the sense of achievement gained through the Good Vibrations project was something new and highlighted that 'achieving' was something they could do and wanted to continue doing. Of course, this is not to say that these men would not have gone on eventually to engage in other education, but they were adamant that participation in this project had set them on this path.

- Emotional and behavioural change

In terms of how prisoners continued to deal with prison life in the months after the project, generally they reported positive outcomes in their behaviour and dealing with personal 
problems, which many felt would have longer-term impacts after their sentence in all areas of their lives:

\author{
“Taking part has given me a push to work harder, I’ve come from a \\ background of drink and drugs and violence and that's all I have ever really \\ known so to feel good about meself in positive way was something new to \\ me.........I'm capable of doing better things."
}

Interestingly, five participants reported being less bored even six months after the project. Unsurprisingly participants felt engaged at the end of the project, and this lack of boredom continued - decreasing only slightly - at least up until the time they were interviewed at six months. It is possible that this is a result of the participants becoming interested in new hobbies and activities. Furthermore, the majority reported decreases in feelings of anxiety. Some attributed this to their increased ability to keep calm, while others suggested that they simply felt more comfortable in their surroundings and with other people. This could be accounted for by the fact that participants had by this time spent longer at this prison and so felt more at ease.

It is worthy of note that one participant, while speaking very highly of his enjoyment of the Good Vibrations project, at the eighteen month follow-up described no changes emotionally or behaviourally - that could realistically be attributed to participation in the Good Vibrations project. What seems relevant here is that this man had been in prison considerably longer than any other participant in this research and so had spent a good deal of time working through personal issues and development needs through his wing community. However, at its most basic level, taking part in the project gave this man what he sought at the time - an interesting diversion and the chance to learn something new. 
- Official data and staff reports

Only two of the participants here had received any adjudications while in this current prison, for both of these this was over two years before participating in a Good Vibrations project. Neither had since received any adjudication reports.

In an attempt to minimise any bias from prison staff who had been involved in one of the Good Vibrations projects, officers were initially asked to think generally about participant's attitudes and behaviour over the past eighteen months, and not in the context of Good Vibrations. Officers had generally very positive things to say about all of these men, and in particular their improvements over the last eighteen months. Reports from participants of decreased shyness and loneliness were supported by wing officers who reported greater social interaction and improved social skills of those who had participated in the project, and officers discussed how the communication skills of most participants had improved, be that more confidence, less abruptness and greater listening skills, or more openness to communicating with other people. Officers also confirmed the educational courses being taken by participants.

\section{Stage Three-Ex-offenders in the community}

While the findings above suggest that some individuals feel that taking part in a Good Vibrations project has a sustained positive impact upon them, what is unknown is whether any of this impact might continue in the long-term when offenders have been released from prison. In order to address this question the findings presented below focus on a sample of 
previous Good Vibrations participants who had previously taken part in a project whilst in prison and have now been released.

The focus of this stage on ex-offenders is a particularly novel and distinct aspect of this study, and of research into the arts in general, and so the findings below are presented as five brief case studies with key themes drawn together.

The project left a strong impression on each of these individuals as they were able to describe the entire project in depth. The focus of this stage of the research, relating to the long-term impact of the project, is discussed in detail below.

\footnotetext{
Stephen $^{11}$, 30s, extroverted/confident personality, self-described as troublesome within prison, took part on a $\mathrm{GV}$ project in a category A prison
}

\section{Key experiences of Good Vibrations}

Although reporting being a self-confident individual, Stephen was keen to highlight the increases in confidence he witnessed in other participants during the project. When probed a little further it became clear that he himself had found the project beneficial in terms of communication and social skills, but in different ways. For example, he explained that it was nice to be able to show his 'soft side' through the project as this was not something he felt able to do in everyday prison life. He spoke of the shock he saw on the faces of prison staff when they came to observe the project and believes they saw a different side to him:

"It showed a different side of me and it let officers see that side. Officers came up and said they didn't know that side of me existed."

Stephen went on to explain that officers began to see him as 'a person', and not just as a trouble-maker. He explained how this opened up new channels of communication for him and how he also felt this was beneficial for prison staff.

On the theme of communication, Stephen noted how the project: 
“...opens people up. The music, the project, and the people working together. Everybody is listened to, everybody is heard. It's about respect."

At the time of interview, Stephen was studying at college. This was something he had planned to do for a long time - before taking part in Good Vibrations - and he reported having taken part in lots of courses in prison. Nonetheless, he did explain appreciating the Good Vibrations as a break from more formal education and highlighted the importance of having that break to give him some thinking space away from what he described as 'boring prison education'.

Paul, 30s, extroverted/confident personality, self-described as troublesome within prison, took part on a $\mathrm{GV}$ project in a category B prison

\section{Key experiences of Good Vibrations}

Paul was also a confident individual, and reported always having been this way. Like Stephen he explained how he had seen other more introverted group members grow in confidence during the Good Vibrations project. Furthermore, he also explained how the project had an impact on his own communication and tolerance of other people. Specifically, he reported how Good Vibrations had opened his mind to viewing other people as individuals - Paul openly discussed how he had only ever mixed with five or six people in prison and made a point of avoiding sex offenders. However, through Good Vibrations he had to communicate with other people and consequently felt able to become more tolerant:

"The course was very intense. All day every day for a week. But it was extremely purposeful because of the concert and I even came to see the sex-offenders as individuals."

These greater levels of tolerance and openness, he explained, continued both in prison and on the outside.

Mark, 30s, introverted/under-confident personality, took part on a GV project in a category B prison

\section{Key experiences of Good Vibrations}

Mark was perhaps the most introverted of the participants who took part in stage three of this 
research, but explained that his confidence had improved greatly in recent years. $\mathrm{He}$ explained how well he bonded with the others in his Good Vibrations group during the project, which was unusual for him as he typically avoided 'social situations'. Mark also highlighted the confidence the course gave him in dealing with prison life in general.

Mark commented that shy people in prison can often be reluctant to take part in any kind of course in prison and would rather 'sit and watch TV', so taking part in a Good Vibrations project in itself was a big step for him. Simply taking part seems to have been a first step towards improving his self-confidence, but this coupled with his positive group experience throughout the course appeared to begin to enhance and cement these improvements in confidence.

Mark discussed his lack of formal education, having no formal qualifications and a generally negative experience of education in his past. However, he appeared very pleased when explaining that he had recently enrolled on vocational courses outside of prison. He highlighted that in prison he only attended education classes where it was compulsory for him to do so, but was now training as a plasterer for his own benefit and actively seeking employment. It is important to note that he did not directly attribute his new found ambition and engagement with education and training to any one project and/or experience, but noted that he felt he had grown in confidence, wished to do something useful with his time, and that in the past he did not have the confidence to attend college.

Tony, 50s, introverted/under-confident personality, took part on a GV project in a category B prison

\section{Key experiences of Good Vibrations}

Tony, like Mark, explained how much he felt 'part of a group' during his Good Vibrations project. Tony discussed this at length and it seems this was particularly important for him as he generally lacked confidence and was not good at 'making friends'. He had felt apprehensive about taking part in the project, but had been encouraged by prison staff to do so, and reported feeling very pleased that he had.

Indeed, while taking part in a Good Vibrations project in itself was a big step for Tony, what is more notable is how quickly he reported finding his voice in the group and realising that he 
could speak out and contribute. Good Vibrations project staff specifically focus on facilitating a focus on listening and giving every group member opportunities to be heard. Tony explained how it is important to be confident in prison, and the course helped him find this confidence.

Undoubtedly taking part in one course is unlikely to turn introverts in extroverts, but some of the men here found their voice in a Good Vibrations group and were able in some small way to continue to build upon this in the future, even outside of prison.

Tony explained that he had a good educational record and this was something he had continued in prison. However, his educational experiences had previously been solitary ones and he noted that he had never done anything like Good Vibrations before or since. Tony was in work at the time of interview.

Peter, 40s, presented as introverted/under-confident personality, took part on a GV project in a category B prison

\section{Key experiences of Good Vibrations}

Peter was unusual in this research - and not just this stage of the research - in that his description of his own confidence levels contrasted with the level of self-confidence and extroversion observed by the researcher. Peter explained being a relatively confident individual but appeared very shy at interview. Nonetheless, he spoke of how the Good Vibrations he took part in was inclusive and allowed all participants to be heard.

While four of the five men mentioned how during the Good Vibrations project they felt more relaxed that they typically did within prison, it was Peter who spoke at most length about the 'humanising' experience of the project. He highlighted the freedom it made him feel, despite being in prison:

"Little things like being able to get coffee when I wanted, to smoke when I wanted, really made me feel normal."

He was keen to highlight that he had never taken part in anything even remotely like Good Vibrations before, but that his participation was an extension of his general involvement in different projects. This is reflected in Peter's reported background of taking part in 
educational programmes both inside and outside of prison.

Discussion implementation, practice and future research

Linking directly to the findings from men in prison, the short case studies presented above demonstrate how the men had much to discuss in relation to two key themes: confidence, communication, and social skills; and the relationship between this and skills development, education, and training. While it is clear that the information presented above is limited and cannot provide a robust picture of the impact of taking part in project like Good Vibrations as offenders move out into the community, the findings remain important to consider. They provide a start-point for further research seeking to investigate how such projects may contribute to changes in the thinking and behaviours of offenders. It is clearly unreasonable to suggest that such projects can be directly responsible for reducing reoffending - and nor do they seek to be - but it remains important to consider how a variety of experiences can be relevant in shaping the path an offender takes towards desisting from crime.

\section{Summary of the findings with male offenders and ex-offenders}

Given the findings discussed above, perhaps the right question to ask is not 'how far are the positive impacts of taking part in a Good Vibrations project sustained long-term' but 'how far have individuals been able to build-upon this positive impact'? The results here suggest that for many participants taking part in a Good Vibrations project appeared to act as a catalyst for change. The feelings of freedom and being 'normal again' engendered by the project appear to give some offenders the mental space to begin making a positive change in their lives. For those men who had recently taken part in their first Good Vibrations project - all of whom 
reported a positive experience of this - we expect that their experience will be similar. However, even where project participants returned to 'normal prison life' after the project, they report taking something of the project with them and for some this seems to act as the beginning of positive change, which they are able to gradually build upon. While not all participants experienced significant individual impacts from the project likely to lead to changes in behaviour, all participants - at a minimum - experienced the project as a positive week of constructive activity.

As discussed earlier, Good Vibrations and projects like it do not seek to have a direct impact on reoffending, and nor did this research seek to measure the impact of the project in this way. However, authors have noted the potential for the arts to contribute to an offenders paths towards desisting from crime (Cox \& Gelsthorpe, 2008; McNeill et al., 2011) and it is important to contextualise the findings presented above in light of academic discussions of desistance. By desistance we mean understanding why and how former offenders avoid continued involvement in criminal behaviour (Maruna \& Immarigeon, 2004; Farrall \& Calverly, 2006) and as Parkes \& Bilby (2010:106) note, the arts can map an "alternative terrain to traditional concepts of rehabilitation and treatment". As highlighted by the findings of this current research, this music project was both responsive to individual need and able to engage some offenders with further education: factors that are respectively vital to engagement and related to lowered risk of future offending (Parkes \& Bilby, 2010). In addition to the above, the broader positive changes highlighted by many participants are important in understanding how the different individual experiences of offenders can contribute to their future life and actions. Elder (1985) discusses 'trajectories' and 'transitions' as central to understanding life course dynamics. He describes a trajectory as a pathway over the 'life span' that is marked by transitions. Transitions are those events, stages 
and processes where changes in the trajectories towards desistance occur. Carlsson (2012) argues that processes of individual change in offending and desistance from crime are complex, "often involving multiple, and context-specific processes" (2012:2). The findings presented here, for some participants, may have prompted changes that help shift the trajectories of their lives.

The interviews conducted with offenders in the community suggest that the findings from this research may extend outside of the prison environment. However, as only a small number of interviews were conducted for this stage of the research, with men who are unlikely to be representative of men in prison more generally, there is a clear need to investigate this further.

\section{Methodological Limitations}

The authors acknowledge that there are potential issues with, and debates around, the research methodology employed here. Researchers must contend with the many practical constraints of conducting research in the criminal justice system and also with debates surrounding the methodologies that may be deemed 'acceptable' by the range of potentially interested parties. For example, many reviews of evidence of 'effectiveness' in criminal justice utilise the principles of the 'Maryland Scale' (Sherman et al, 1997) to assess the scientific evidence surrounding the impact of a particular intervention (for example, see Butler, Hodgkinson, Holmes, \& Marshall 2004). Sherman et al. propose that robust evidence of causality can only be shown by studies using a robust comparison group design. However, this raises a number of issues around what 'effectiveness' means in the context of the arts in criminal justice - and this is likely to be different things to different groups - and what therefore it is appropriate to measure.

An experimental, randomised control trial design would not have been appropriate for this 
study, given the overall aim of this particular study which was to capture the experience of taking part in a Good vibrations project in the participants own words. It is appropriate and meaningful to track an offender's journey against their own past. Clearly it must also be acknowledged that there are potential issues with self-report data, but the inclusion of reports from prison staff and the reviewing of OASys data and adjudication reports provides a strong form of data triangulation. It is still true that participants may to some extent report what they feel the researchers want to hear, but where attitudinal and behavioural change have also been observed by prison staff this can be taken as a strong indicator that the change is real. The research aimed to capture the voices of those who had participated in the GV project and their own reports of changes, and did not seek to look at reoffending rates for a number of reasons: most arts-based programmes do not aim to directly reduce reoffending, but aim to provide participants with certain skills that may help them embark on a more positive life journey; and finally, binary measures of reoffending tell us nothing of the ways that individuals experience any impacts of a project.

The sample of participants at the second prison and in the community is small and therefore unlikely to be representative of every individual who has taken part in one of these projects. Furthermore, these samples were not tracked over time. It is also likely that, given their choice to take part in this research, these participants were the most motivated of the group and therefore much more likely to report positive outcomes and this should be borne in mind. Despite this, these samples are able to give us some indication of the effect that the project may have on some individuals. In addition, the participants in the community come from a range of prisons, having a range of different experiences that mirror many of the experiences of ex-offenders. 


\section{Conclusions}

The results presented throughout this article suggest some common themes in the way different groups and individuals experience taking part in a Good Vibrations project. This research in particular builds upon the findings of previous evaluations of Good Vibrations and furthermore, the findings from all samples to a large extent complement and extend one another.

The findings suggest that participating in this particular project can act as a stepping-stone into further education. This is particularly interesting given that many offenders have poor educational backgrounds and are often reluctant to engage with formal education in prison, yet poor educational achievement is linked to increased risk of re-offending. Reluctance to engage in prison education may in part be due to feelings of dislike of the education system in general, but is often also due to feelings of inadequacy and fear of failure (Wilson \& Reuss, 2000). Here, participants reported a sense of achievement at completing the project and for some participants this may be the first time they have ever really achieved anything. Perhaps most interesting is the finding that the initial positive changes observed in some individuals seem to prompt continued positive change. Indeed, of those men whom we were able to make contact with in the community after their release from prison - most of whom had completed the Good Vibrations project at least twelve months beforehand - they were still reporting positive attitudinal changes that they suggested were prompted by their initial participation in the project. It may of course be that participants have on some level already decided to make positive changes in their behaviour, but the results from this research highlight how projects such as Good Vibrations may act as a catalyst for future behavioural change for some individuals. Participating in the project gives some people the skills, for example improved social skills, also found by Digard, et al., (2007) review of a Good Vibrations projects, to go on and make a positive change, be that learning how to cope with 
prison life, or going on to take part in formal education programmes. Clearly every individual is different, and changes will not happen for all, but many offenders point to a specific time they made a decision to change their behaviour, or something that prompted this decision. A sizeable amount of prison-based treatment focuses on cognitive restructuring (cf. Andrews \& Bonta, 2003), and while there is clearly a complex interplay of internal and external factors that must fit into place for offenders to make a decision to change and stick to that (LeBel, Burnett, Maruna, \& Bushway, 2008), it is possible that projects such as that reviewed here may prompt positive change for some offenders. The findings presented here are, as both Nee (2004) and Liebling and Maruna (2005) highlight is important in research in criminal justice, centred on the experience of offenders and ex-offenders. Furthermore, the findings suggest that participation in the arts may 'inspire desistance' for some offenders (McNeill et al., 2011). While the findings of this research do not suggest that participation in the arts offers a clear and direct path towards desistance, they do suggest that for some offenders the arts may encourage changes that set them on the complex path towards desisting from crime. This change can come directly from taking part in creative activities and also from the by-products of such activities including improvements in self-esteem and self-confidence, communication and social skills. However, this must all be viewed in the context of the value of the arts as a humanising experience. Participation in arts projects is unlikely to directly reduce offenders' likelihood of reoffending, and nor are they intended to do so, but at a basic level the findings of this research demonstrate the way such projects provide offenders with a humanising experience, too often lacking in prisons.

While the evidence presented here on the impact of arts-based project post-release is limited by sample size, the findings do suggest that, at least in prison, arts-based programmes can promote positive change for some offenders., Given the emerging evidence of the potential impact of arts based programmes, now seems the time for a serious consideration of how arts 
programmes can work together with traditional programmes to best target offenders' need and risk.

The authors acknowledge that there are limitations to this research. Methodological limitations and considerations are discussed in the methodology section of this article. Additionally, while the research objectives laid out earlier in this paper were largely achieved, the samples from the second prison and community were regrettably smaller than had initially been hoped, which is not unsurprisingly given the challenges of research in the criminal justice system and with ex-offenders.

With reference to the discussion within the methodology of how evidence of 'effectiveness' of interventions with offenders is best sought, we argue that it is entirely appropriate and meaningful to track an offenders journey against their own past. Furthermore, that to measure the impact of arts-based programmes on reoffending rates is clearly unreasonable. Such programmes do not seek to directly reduce reoffending, but may aim to contribute to changes in the thinking and behaviours of offenders and it remains important to consider how a variety of experiences can be relevant in shaping the path an offender takes towards desisting from crime. This research has begun to map this journey in relation to one particular artsbased project. 


\section{References}

Albertson, K. (2015). Creativity, Self-exploration and Change: Creative Arts-based Activities' Contribution to Desistance Narratives. The Howard Journal of Criminal Justice, 54, 277-291.

Allen, K., Shaw, P. and Hall, J. (2004). The Art of Rehabilitation: Attitudes to Offenders' Involvement in the Arts. London: Esmée Fairburn Foundation.

Andrews, D. A. and Bonta, J. (2003). The psychology of criminal conduct, 3rd ed. Cincinnati, $\mathrm{OH}$ : Anderson.

Armstrong, D., Gosling, A., Weinman, J., and Marteau, T. (1997). The place of inter-rater reliability in qualitative research: an empirical study. Sociology, 31(3), 597-606.

Bilby, C., Caulfield, L.S., and Ridley, L. (2013). Re-Imagining Futures: Exploring arts interventions and the process of desistance. Final grant report for the Arts Alliance.

Blacker, J., Watson, A. and Beech, A. (2008). A combined drama-based and CBT approach to working with self-reported anger aggression. Criminal Behaviour and Mental Health, 18, 129-137.

Butler, G., Hodgkinson, J., Holmes, E., and Marshall, S. (2004). Evidence Based Approaches to Reducing Gang Violence. Government Office West Midlands and Home Office Research Team.

Carlsson, C. (2012). Using turning points to understand processes of change in offending, British Journal of Criminology, 52 (1), 1-16.

Caulfield, L.S. and Hill, J. (2014). Criminological research for beginners: a student's guide. London: Routledge, UK.

Cox, A. and Gelsthorpe, L. (2008). Beats and bars - Music in prisons: An evaluation. The Irene Taylor Trust. 
Cox, A. and Gelsthorpe, L. (2012). 'Creative Encounters: Whatever Happened to the Arts in Prisons?' in L. K. Cheliotis (ed) The Arts of Imprisonment, Farnham: Ashgate, 257276.

Digard, L., Grafin von Sponeck, A. and Liebling, A. (2007). All Together Now: The therapeutic potential of a prison-based music programme. The Prison Service Journal, 170, 3-14.

Eastburn, C. (2003). Gongs behind bars: Evaluation report of the Good Vibrations Gamelan in Prisons pilot project 2003. Wellingore: The Firebird Trust.

Elder, H. (1985). Methods of life course research: Qualitative and quantitative approaches (5-27), Thousand Oaks, CA: Sage.

Farrall, S. and Calverley, A. (2006). Understanding desistance from crime. Berkshire: Open University Press.

Henley, J. (2009). Learning Gamelan: A teacher's experience. National Association of Music Educators magazine, 2010.

HM Prison Service (2015). What we do. Retrieved $23^{\text {rd }}$ June 2015 from https://www.gov.uk/government/organisations/hm-prison-service

Jupp, V., Davies, P. and Francis, P. (2006). Doing Criminological Research. London: Sage.LeBel, T.P, Burnett, R., Maruna, S., and Bushway, S. (2008). The `Chicken and Egg' of Subjective and Social Factors in Desistance from Crime. European Journal of Criminology , 5, 131-159.

LeBel, T. P., Burnett, R., Maruna, S. and Bushway, S. (2008). ' The 'chicken and egg' of subjective and social factors in desistance from crime', European Journal of Criminology, 5, 131- 159.

Liebling, A. and Maruna, S. (eds) (2005). The Effects of Imprisonment, Cullompton, Devon: Willan Publishing. 
Maruna, S. and Immarigeon, R. (2004). After Crime and Punishment. Devon: Willan Publishing.

McNeill, F., Anderson, K., Colvin, S., Overy, K., Sparks, R. and Tett, L. (2011). Inspiring Desistance? Arts projects and 'what works?'. Available: http://blogs.iriss.org.uk/discoveringdesistance/files/2011/09/McNeill-et-al.-2011$\underline{\text { Inspiring-Desistance.pdf }}$

Miles, A. and Clarke, R. (2006). The arts in criminal justice: A study of research feasibility. University of Manchester: Centre for Research on socio cultural change.

Ministry of Justice (2008). Third sector strategy: Improving policies and securing better public services through effective partnerships, 2008-2011. London: Ministry of Justice.

Ministry of Justice (2010). Breaking the Cycle: Effective punishment, rehabilitation and sentencing of offenders, Ministry of Justice: London. Available at http://webarchive.nationalarchives.gov.uk/20120119200607/http:/www.justice.gov.uk /consultations/docs/breaking-the-cycle.pdf

Ministry of Justice (2013). Transforming rehabilitation: a summary of evidence on reducing re-offending' Ministry of Justice: London. Available at https://www.gov.uk/government/publications/transforming-rehabilitation-a-summaryof-evidence-on-reducing-reoffending

National Offender Management Service (2012). NOMS Commissioning Intentions for 201314: Negotiation Document, NOMS: London. Available at http://www.justice.gov.uk/about/noms/commissioning

Nee, C. (2004). The offender's perspective on crime: Methods and principles in data collection. In A. Needs and G. Towl (Eds.), Applying psychology to forensic practice. Oxford: BPS Blackwell. 
Owers, A. (2008). Prisons and the prevention of reoffending. Centre for Criminal Justice Studies Frank Dawtry Memorial Lecture, University of Leeds.

Parkes, R. and Bilby, C. (2010). The Courage to Create: The Role of Artistic and Spiritual Activities on Prisons. The Howard Journal of Criminal Justice, 49, 97-110

Prison Reform Trust (2013). Bromley Briefing prison factfile. London: Prison Reform Trust. Reuss, A. (1999). Prison(er) Education. The Howard Journal of Criminal Justice, 38,113127.

Scottish Prison Service (2012). Freedom of information request obtained by the Scottish Conservatives. Available at: http://www.scottishconservatives.com/2012/12/literacy$\underline{\text { crisis-in-scotlands-jails/ }}$

Sherman, L., Gottfredson, D., MacKenzie, D., Eck, J., Reuter, P. and Bushway, S. (1997). Preventing Crime: What Works, What Doesn't, What's Promising. Washington: US Department of Justice

Wilson, D., Caulfield, L.S., and Atherton, S. (2009). Good Vibrations: The long-term impact of a prison based music project, The Prison Service Journal, 182, 27-32.

Wilson, D. and Reuss, A. (2000). Prison(er) education: stories of change and transformation. Water Side Press: London.

Wilson, D. and Logan, M. (2006). Breaking Down Walls - The Good Vibrations Project in Prison. Birmingham: Centre for Criminal Justice Policy and Research. 
Table 1 - The Research Process

\begin{tabular}{|c|c|}
\hline Stage & Process \\
\hline $\begin{array}{l}\text { Stage One }^{\text {iii }} \\
\text { Recent Good } \\
\text { Vibrations participants }\end{array}$ & $\begin{array}{l}\text { - Offenders who had taken part in the most recent Good Vibrations project were contacted. } \\
\text { - Interviews were conducted with participants about their general attitude and behaviour. } \\
\text { Prison staff were interviewed to validate reports from prisoners and also to comment on } \\
\text { participants' general attitude and behaviour, and any changes in these that they may have } \\
\text { observed. } \\
\text { - Adjudication reports were reviewed, with the consent of each participant. }\end{array}$ \\
\hline $\begin{array}{l}\text { Stage Two } \\
\text { Following up previous } \\
\text { research participants }\end{array}$ & $\begin{array}{l}\text { - Participants who had taken part in previous research (Wilson et al., 2008) were contacted. } \\
\text { - Interviews were conducted with participants about their general attitude, experiences and } \\
\text { behaviour. } \\
\text { - Prison staff were interviewed to validate reports from prisoners and also to comment on } \\
\text { participants' general attitude and behaviour, and any changes in these that they may have } \\
\text { observed. } \\
\text { - Adjudication reports were reviewed, with the consent of each participant. }\end{array}$ \\
\hline $\begin{array}{l}\text { Stage Three }^{\text {iv }} \\
\text { Ex-offenders in the } \\
\text { community }\end{array}$ & $\begin{array}{l}\text { - Using details provided by Good Vibrations, the research team identified male offenders who had } \\
\text { previously taken part in a Good Vibrations project and had indicated they would have been } \\
\text { released by this time. } \\
\text { Participants were interviewed either face-to-face or telephone interviews to discuss their } \\
\text { experiences of taking part in the project and any impact their participation had upon them. }\end{array}$ \\
\hline
\end{tabular}




\footnotetext{
${ }^{\mathrm{i}}$ OASys is a need and risk assessment used throughout the prison and probation service in England and Wales
}

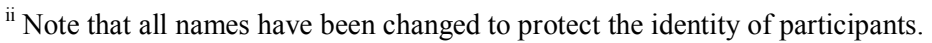

iii Note on Stage Two: Fourteen participants took part in the Good Vibrations project most recent to the research visits. The research team hoped to interview as many of these participants as possible as well as speak with wing staff. While the researchers were able to speak to the majority of new participants at the prison involved in Stage One of the research, only two participants were able and willing to be interviewed at the second prison. This was due to organisational issues within the prison. Both of the participants who were interviewed were adult males, aged 25 and 35 and were due for release within the next six months. Of note is that two of the 'new' project participants had taken part in a project previously and were included in Stage One of this research. Four of the new Good Vibrations participants were interviewed. Two men could not take part in the research due to their prison work commitments. Interestingly, only the two men with medium risk scores had a history of adjudications at the prison, both having been found guilty of three adjudications each during 2006 and 2007. Receiving this number of adjudications in a less than twelve month period is relatively unusual and suggests that these two men had a history of trouble-making within the prison. Indeed, during interview both of these participants were open about their history of bad behaviour, and their tendency towards anger and getting involved in conflict situations.

iv Note on Stage Three: At the time of interview, four of these participants had taken part in a Good Vibrations project between thirteen and eighteen months ago. One of the men had taken part in the project only seven months ago. Despite falling outside of our definition of 'long-term' it was clearly important and relevant to include this participant as his experiences of moving from prison into the community were the main focus of this stage of the research. As far as we can ascertain, all of this group were medium or high-risk. The men interviewed presented a range of different personality types and experiences of prison life. Two men presented as particularly confident and their brief description of their experiences of prison life adds weight to this. Both of these men discussed how they had at times been a source of trouble for prison staff and presented what can be best described as a 'hard-man' persona within prison. Of the other three men, two openly discussed their general levels of introversion and shyness while one man suggested he was relatively confident but did not present as confident throughout the interview. 
Title: Exploring alternative terrain in the rehabilitation and treatment of offenders: findings from a prison-based music project

\title{
Key Words:
}

Arts in prison; rehabilitation; treatment; offender's voices;

\section{Running header:}

Arts based contribution to rehabilitation

\begin{abstract}
:
The arts in prison settings have provided an alternative or complimentary component to rehabilitation. Despite increased interest, studies capturing the voice of offenders participating in projects and the long-term impact are limited. Data from semi-structured interviews with 18 men, who had taken part in a music-based project while incarcerated, including one group of five participants who were tracked for 18 months with supplemented data from correctional staff and official documentation is presented. Participants of the artbased projects comment on changes they believe to have derived from participating in the project, particularly relating to emotions, self-esteem, self-confidence, communication and social skills. An ex-offender sample of participants reported that participation in art projects provide experiences that promote beneficial skills that have been useful for post prison life.
\end{abstract}




\section{Introduction}

Arts based projects have a long and complex history of work with offenders (Cox \& Gelsthorpe, 2012) and anecdotal evidence suggests that arts in prison programmes can have a significant effect on offenders who take part in them - on their well-being, self-esteem, behaviour, treatment engagement, and engagement with further learning. Research on the arts in criminal justice has begun to provide an evidence base, suggesting arts projects can and do have a positive impact on offenders - for example, on their anger and aggression (Blacker, Watson, \& Beech, 2008), and potentially on helping offenders work towards non-offending futures (Bilby, Caulfield, \& Ridley, 2013; Cox \& Gelsthorpe, 2008). However, there remains a paucity of research on the role of the arts in criminal justice and in particular few studies have investigated the longer-term impact of arts programmes on offenders after participating in a project.

\section{The role of the arts}

While prison interventions typically focus on reducing reoffending, there is a growing appreciation for the role of non-traditional programmes and their impact, particularly in engaging prisoners in more formal treatment and education programmes. One such area of interest is the growing optimism about the role of the arts. Parkes and Bilby (2010) have charted how arts and spiritual interventions with prisoners, as opposed to interventions based on psychology, training or education can map an "alternative terrain to traditional concepts of rehabilitation and treatment", and suggest that we should have the courage to allow prisoners to "create" (Parkes \& Bilby, 2010: 106). Given the varying needs of those in prison, the range of inputs is likely to be required to address the variety of needs effectively. In the United Kingdom - where the research presented in this paper was conducted - the criminal justice governing bodies believe that learning opportunities need to address responsiveness 
and diversity issues (Ministry of Justice, 2013; National Offender Management Services, 2012) and there has been some recognition of 'the important role that the arts, collectively, can play in the rehabilitation process' (Ministry of Justice, 2010: 19). Prisoners with low literacy levels can be reluctant to engage with the 'basic skills' programmes offered in prisons. These kinds of formalised educational courses can seem similar to the education they were reluctant to engage with at school (Wilson \& Caulfield, 2009). Furthermore, many formal rehabilitation programmes are inaccessible for offenders with a low IQ (Prison Reform Trust, 2013). For these individuals, arts-based programmes that show them they can achieve may act as the first step towards further, more formal, education and training (Wilson \& Logan, 2006). It is suggested that up to $80 \%$ of prisoners in many Western countries have poor literacy (Scottish Prison Service, 2012) and that educational background is statistically associated with risk of re-offending. Owers (2008) and Reuss (1999) argue that creative and innovative ideas are needed in order to help prisoners benefit from the wider impact of education and also to engage them in such processes in the first instance, given that many prisoners are "failed learners".

Aside from considering the potential of the arts in engaging offenders, it is important to also consider the humanising effect on individuals taking part in arts programmes. Prison incarcerates offenders but also aims to rehabilitate and provide purposeful activity (HM Prison Service, 2015). Engaging with the arts in prison environments has been described by Allen, Shaw, and Hall (2004) as a "humanising experience", which enables prisoners to acquire educational achievements and also improves self-confidence, social skills and personal development. Increasing offenders' self-esteem, communication skills, and selfworth have value in their own right and arts programmes have been shown to tackle these areas (Cox \& Gelsthorpe, 2008; Miles \& Clarke, 2006). 
Despite increased interest in the role of the arts in offender rehabilitation, Albertson (2015) contends that the literature has omitted to include the experience of the experts themselves in the form of the testimony of the prisoners accessing these projects. Bilby et al. (2013) provide a recent exception to this, including a cross-section of adult and juvenile, male and female offenders involved in a variety of arts-based programmes. While Bilby et al. reported a range of positive outcomes for the offenders in their sample, they were unable to investigate whether any of their findings were sustained in the longer term.

\section{Good Vibrations}

Good Vibrations presents an example of a charity providing a service beyond the remit of 'traditional' education and training providers, using a unique form of music training and group work. Good Vibrations uses gamelan percussion music from Indonesia that has been identified as suitable for community or group settings; it has an informal and inclusive approach; and includes a variety of instruments that can be played without any prior musical training or knowledge of musical notation (Eastburn, 2003). It is a particularly communal form of music-making where participants are compelled to work together (Henley, 2009). Good Vibrations projects typically run over one week for around fifteen-to-twenty offenders on average. As well as learning how to play traditional pieces of gamelan music, participants create their own compositions as a group. They also learn about Indonesian culture and associated art forms (e.g. shadow puppetry, Javanese dance). At the end of the week, offenders perform a concert to which staff, peers, family members and others are invited. A number of small-scale reviews of Good Vibrations have been carried out (Digard, Grafin von Sponeck, \& Liebling 2007; Eastburn, 2003; Wilson \& Logan, 2006). Digard et al., (2007), suggested there were positive impacts on those who participated in a Good Vibrations 
project, including increased insight and reflection, and also stronger cohesion in groups of prisoners.

Research by Wilson and Logan (2006) suggests that taking part in the gamelan sessions and successfully completing the whole week empowered prisoners to seek further education and training opportunities. This was attributed to the 'uniqueness' of Good Vibrations and the inclusive approach of the tutors, which enabled prisoners to develop social skills to work together and also discuss wider issues during the sessions. Wilson and Logan also suggested that Good Vibrations projects removed the barrier of intimidation towards engaging in education for many prisoners. Prisoners' self-esteem and confidence were also reportedly increased, to the extent that many talked of not just wanting to change but also feeling they had the capacity and ability to do so (Wilson \& Logan, 2006).

The findings highlighted above suggest that Good Vibrations projects may have a positive impact on specific groups, but, given the small-scale and short-term focus of these reports, also draw attention to the need for further research to investigate how far these findings can be generalised and whether any impact is sustained long-term in the lives of offenders.

\section{Research objectives and aims}

In light of recommendations that effective research into the arts should track participants over time (Miles \& Clarke, 2006), and against the background of previous research, the overall objective of this study was:

- To consider and capture the experience of taking part in the Good Vibrations project over an eighteen month period through self-reflections (in their own words). In particular the aims were; 
- To capture participants' reflections particularly with respect to changes in attitudes, emotions and behaviour

- To consider official documentation and reports from prison staff to triangulate.

- To track participants' engagement with further learning, education and selfdevelopment.

- To compare the findings from the original sample of participants to other groups of project participants.

- To follow a sample of male participants from a variety of prisons as they move out into the community.

\section{Method}

\section{Design}

\section{The research was conducted in three stages:}

- Stage One involved evaluating a new cohort of recent project participants, in order to increase the validity of the findings of previous research.

- Stage Two considered the long-term impact of the Good Vibrations project to offenders who had taken part in previous research as they progressed through the prison system.

- Stage Three reviewed the effects of the project on participants from a variety of prisons as they moved out into the community. 


\section{Participants}

Participants were recruited from two Category B English Prisons that had recently hosted a Good Vibrations Project, along with a sample of ex-offenders who had left prison and were living in the community. Category B prisons house offenders that do not require maximum security but who still pose a moderate amount of risk and therefore require fairly high security. Table 1 details the research process in stages along with the number of participants available and recruited.

\footnotetext{
**Insert Table 1 about here**
}

\section{Inclusion and exclusion}

For the purposes of this research, females, young males, and those who had been patients in secure units were not contacted as the aim at this stage was to begin to build upon the existing evidence on the impact of the project with adult men in prison. In all, collecting data on male participants in this way begins to review on a broader scale the experiences and effects of participating in a Good Vibrations project on male offenders. Therefore, it is possible to suggest that any positively impactful experiences reported by ex-offenders about taking part in the project may also in the future be experienced by the current offenders who have taken part in this research.

\section{Recruiting ex-offenders}

The research team were aware from the start that contacting ex-offenders is notoriously fraught with difficulties (Jupp et al., 2006). However, with the assistance of Good Vibrations a database of thirty-three men who fit the project criteria was compiled. Of these thirty-three, we were able to interview five men. Many of the phone numbers and email addresses were 
incorrect, some of the men had not been released as early as they had hoped and so were still in prison, and despite weeks of trying, we could not get an answer from some of the numbers. The five men whom we were able to gain contact with were very helpful and appeared eager to be involved in the research. Four face-to-face interviews and one telephone interview were conducted. It should be noted that the findings below are based on self-report and it has not been possible to corroborate the facts, other than the information from Good Vibrations confirms the prison they were in at the time of taking part in a project.

\section{Materials}

\section{Semi-structured interviews}

The interview schedules were based on those used in previous research (Wilson, Caulfield, \& Atherton, 2009) and amended for use at the different stages of this research, including interviews with ex-offenders. Subsequent interviews were conducted 6 months and 18 months after completing the Good vibrations project. Participants were interviewed at length and were asked: to describe their experiences of the project; what they gained from it; and specifically to focus on their experiences and behaviour after the project. The duration of the interviews was generally between one hour to one hour and a half. In order to help enhance each participant's memory of the Good Vibrations project, the researcher asked them to talk through the week explaining why they took part, how they found the course, the involvement of staff in the course and so on. Participants were also asked to explain various aspects of their behaviour, attitudes, and activities in the months since completing the project. Participation was voluntary and therefore no compensation was given for taking part. The participant consent form detailed that participation was entirely voluntary and that those who did choose to participate were "free to withdraw at any time without giving any reason, without my parole, standard of care, rights or privileges being affected". 


\section{Informal interviews with prison staff}

Interviews were conducted with prison staff. These interviews were 'informal' as for pragmatic reasons they were conducted on an 'ad-hoc' basis rather than scheduled basis to fit around the individual's diary for that day. The purpose of these interviews were to assess the quality of the information gained from interviews with the prisoners, and to provide a modest form of internal data triangulation, prison officers in regular contact with the participants were interviewed about their views generally about these individual men and specifically about their attitudes, behaviour, and activities over the past six and twelve months. Given the complexities of prison-based research, it was not possible to interview the same prison officers at the six and eighteen month follow-up. In total eight prison staff participated in the research interviews: two at the prison involved for stage two only; six at the original prison (one wing officer interviewed for each wing where participants resided).

All interviews were conducted on a one-to-one basis by one of the researchers either in the participating prisons or at a suitable public place in the community. Interviews were digitally recorded and transcribed.

\section{Offender Assessment System (OASys) and adjudication reports}

The research team was granted access to each participant's OASys ${ }^{\mathrm{i}}$ data and adjudication reports. The prison research co-ordinator and each individual participant agreed to this. The OASys data was collected to provide background and risk-level data on participants. Any breaking of prison rules is typically dealt with by issuing adjudications in prison, therefore adjudication data were collected to monitor numbers of adjudications before and after taking part in a Good Vibrations project. 


\section{Ethics}

This project gained ethical approval by Birmingham City University's Psychology Research Committee

\section{Data analysis}

The lead researcher produced the transcript of the interviews and conducted the data analysis. A thematic analysis approach was taken, beginning with an in-depth coding process involving the entire body of interview data (Caulfield \& Hill, 2014). The coding was initially led by themes identified through the literature, noted by the researcher during interviews, when listening to recordings, in the transcription process, and reading transcripts. These themes acted as a basis for coding, supplemented by new themes emerging during the coding process. Armstrong, Gosling, Weinman and Martaeu (1997) support that the thematic analysis process is robust and a singular researcher analysis produces meaningful and reliable results, however, any differentiation that is found usually relates to the packaging of the results. That said, the overall packaging of results has been accomplished through collaboration between the authors.

\section{Results}

The results below are presented by stage, under the thematic headings identified from the data.

\section{Stage One - Recent Good Vibrations participants}

The findings presented below add support to previous research on the impact of Good Vibrations and suggest that the findings with the initial sample are not unique to that group of 
participants. All participants reported finding the experience enjoyable and beneficial. They were extremely positive about the Good Vibrations staff and described the week in a vivid amount of detail. There are a number of areas where the effects of the project were felt deeply. These are discussed below.

\title{
Anger reduction and improved relaxation
}

Anger and aggression were over-riding issues for two of the men interviewed in this stage of the research. Both reported that they expected to become involved in some form of conflict with either group members and/or Good Vibrations staff throughout the week as this would be usual for them. However, this did not happen and this surprised these men.

\author{
"I would recommend the project, especially for people with emotional \\ issues. Not just for anger, you've got self-harmers too. I was going through \\ a bad patch, where I was getting those angry thoughts and self-harm \\ thoughts, and for that week I just didn't get none of it. I was just...it was \\ chilled."
}

\begin{abstract}
Furthermore, even those men with no reported anger or aggression problems explained how relaxing the project was and how this sense of calm helped them deal with prison life during that week but also in the days that followed.
\end{abstract}

\footnotetext{
"It had a bigger impact initially, and then I've had to incorporate that impact into daily life on the wing...It's definitely had an impact on daily life, on how I try to chill. Like now I try to take an hour a day a to relax..."
} 
Participants stated that they did not expect to experience any positive mood changes, but they did and these were significant. Two men reported that it allowed them to channel calm feelings instead of angry ones. All of the men described how they have continued to listen to the $\mathrm{CD}$ they were given and they use this to relax:

\author{
"My Gamelan CD has had more use than any other CD in my cell. And it's \\ not really my sort of thing, but if you're stressed you just sort of chill."
}

\title{
Communication and social skills
}

One of the most significant findings here was the increase in communication and social skills reported by participants. Participants reported that the project had enhanced their listening skills, allowed the more introverted participants the space to find their voice in the group, and also brought the men together as a group. Overall the participants felt the group had worked well together and bonded. One participant commented that he would be able to apply these group-work skills to life outside prison in dealing with people he might otherwise not get on with - 'you put your differences aside to get the job done.' The men felt the praise they were given after the concert and the huge sense of pride and achievement increased their confidence and self-esteem a great deal.

Interestingly, it was one of the men who had previously taken part in this research and who had one of the most difficult life histories of anyone we spoke to that expressed how Good Vibrations had helped him learn to trust people. This was echoed here by another participant with a difficult history.

\section{Level of impact}


All four participants explained the sense of freedom the project had given them - 'like being normal again'. For three of the four men here, the project highlighted the positive benefits of using their time constructively and doing something meaningful. For one of the men here, and one of the men interviewed at Stage One, the project appeared to have had little effect beyond that of a week's calming distraction from prison life and a relatively fulfilling experience. However, these men reported having already developed the skills others have gained from the project. Despite this both saw that the project can impact on other people in a much more significant way. That the project was a good experience for these men is a positive finding, however others have reported that the project was the beginning of longlasting positive changes. As one participant put it "I've gained so much from this, but now it's on me to build on these skills".

\section{Staff reports}

Staff confirmed reports from the men. The two men with anger and aggression issues were described as such by staff, but staff also noted that during the project these men had been much calmer and less argumentative. The least confident of the participants was reported to typically have problems taking praise or criticism, but was dealing with this much better. In general staff discussed the project in terms of the positive impact it has on participants at the time and of how much enjoyment they got out of it, but they did not report feeling it had any longer-term impact on participants. When probed some staff saw that for a few of the men who have taken part previously it helped with their confidence issues. 


\section{Stage Two - Tracking participants over eighteen months}

It is interesting to note that all participants who were interviewed highlighted the impact the project had made upon them, over and above the other activities within the prison.

Participants described initially feeling apprehensive about the project, particularly about the idea of performing a concert at the end of the week. However, they quickly felt at ease in the group and experienced a great sense of achievement after performing the concert. All participants talked positively about their experiences of the project and overall it seems that for all but one of the participants they were able to use this experience as the building blocks for further personal development.

\section{Confidence, communication, and social skills}

Perhaps one of the most significant findings to emerge from this research is the general improvement in social network and communication skills reported by participants and observed by prison staff. These improvements are sustained for up to eighteen months, at least in the prison setting. Participants reported an increased empathy and bond with other participants and staff, which translated into a willingness to communicate with a wider variety of fellow prisoners.

\footnotetext{
"It brings people together who you would never ever talk to...brought everyone together, we had mutual ground."
}

Participants spoke of the importance of developing skills beyond that of learning to play instruments, namely listening and communication skills, which with hindsight, many reported they never really had before. Of particular note is how the project altered participants' perception of others, making them feel more comfortable around people they had not met 
before. At the eighteen month follow-up, six of the men had maintained and developed close friendships with others from the group, and through this developed new friendships with other men from their friend's wings. Some of these men had stated that before the project they would not have spoken to some of those that they now held close friendships with specifically because they were from 'the sex-offenders wing'.

For security reasons prison staff were required to be present during the project. The impact of this on prisoners' perceptions and relationships with staff was an important outcome of the Good Vibrations project as afterwards they felt they had something in common. This enabled a relationship of trust to develop between staff and prisoners, as prisoners began to see staff as 'human' rather than 'just a uniform':

\footnotetext{
"Previously, I despised staff, see them as authority, never really got into talking to them but now am on first name basis, interacting a lot more because [during the project] I didn't just see them as staff I saw them as people. That was a big eye opener."
}

Prisoners also reported that relationships with other staff who had not been involved in the project improved. Seemingly once prisoners begin to see past the uniform, they are able to judge all prison staff as individuals. At the six month and eighteen month follow-up both participants and staff reported that these improvements in relations had been sustained.

\section{Skills development, training and education}

All participants expressed a great degree of pride and sense of achievement at having completed the course, and in particular having had the courage to take part in the concert in front of fellow prisoners and staff on the final day. In the past many participants had started 
other courses or programmes that for various reasons they had not completed. Completion and presenting their skills gave participants 'a sense of achievement and wellbeing'. As a result of this sense of achievement, six months after completing the project participants stated they were more confident to learn other things and more open to the idea of developing other skills.

For some, this sense of empowerment had encouraged them to consider other courses and they had begun to be proactive at learning other skills. This was demonstrated by one participant who contacted the county library to get more information on Indonesian culture. Others had taken part in and made active moves towards educational courses offered within the prison.

Participants compared the project to a range of other courses, both educational and artsbased. Some reported they felt other courses were inflexible and didn't allow participants to have a voice and express their opinions. The personal gains from Good Vibrations were cited as being as important as learning practical skills or educational attainment, but also served to highlight that learning had taken place in a highly enjoyable and rewarding way. This enjoyment, combined with the sense of achievement, encouraged the moves towards further learning, training and education mentioned above. One participant succinctly described the Good Vibrations project as 'a stepping-stone to other education'. At the eighteen month follow-up three of the men who had previously been reluctant to engage with education were now working towards recognised qualifications.

\section{Emotional and behavioural change}

In terms of how prisoners continued to deal with prison life in the months after the project, generally they reported positive outcomes in their behaviour and dealing with personal 
problems, which many felt would have longer-term impacts after their sentence in all areas of their lives:

\author{
“Taking part has given me a push to work harder, I've come from a \\ background of drink and drugs and violence and that's all I have ever really \\ known so to feel good about meself in positive way was something new to \\ me.........I'm capable of doing better things."
}

Interestingly, five participants reported being less bored even six months after the project. Unsurprisingly participants felt engaged at the end of the project, and this lack of boredom continued - decreasing only slightly - at least up until the time they were interviewed at six months. Furthermore, the majority reported decreases in feelings of anxiety. Some attributed this to their increased ability to keep calm, while others suggested that they simply felt more comfortable in their surroundings and with other people. It is worthy of note that one participant, while speaking very highly of his enjoyment of the Good Vibrations project, at the eighteen month follow-up described no changes - emotionally or behaviourally - that could realistically be attributed to participation in the Good Vibrations project. What seems relevant here is that this man had been in prison considerably longer than any other participant in this research and so had spent a good deal of time working through personal issues and development needs through his wing community. However, at its most basic level, taking part in the project gave this man what he sought at the time - an interesting diversion and the chance to learn something new.

\title{
Official data and staff reports
}


Only two of the participants here had received any adjudications while in this current prison, for both of these this was over two years before participating in a Good Vibrations project. Neither had since received any adjudication reports.

In an attempt to minimise any bias from prison staff who had been involved in one of the Good Vibrations projects, officers were initially asked to think generally about participant's attitudes and behaviour over the past eighteen months, and not in the context of Good Vibrations. Officers had generally very positive things to say about all of these men, and in particular their improvements over the last eighteen months. Reports from participants of decreased shyness and loneliness were supported by wing officers who reported greater social interaction and improved social skills of those who had participated in the project, and officers discussed how the communication skills of most participants had improved, be that more confidence, less abruptness and greater listening skills, or more openness to communicating with other people. Officers also confirmed the educational courses being taken by participants.

\section{Stage Three - Ex-offenders in the community}

While the findings above suggest that some individuals feel that taking part in a Good Vibrations project has a sustained positive impact upon them, what is unknown is whether any of this impact might continue in the long-term when offenders have been released from prison. In order to address this question the findings presented below focus on a sample of previous Good Vibrations participants who had previously taken part in a project whilst in prison and have now been released. 
The focus of this stage on ex-offenders is a particularly novel and distinct aspect of this study, and of research into the arts in general, and so the findings below are presented as five brief case studies with key themes drawn together.

The project left a strong impression on each of these individuals as they were able to describe the entire project in depth. The focus of this stage of the research, relating to the long-term impact of the project, is discussed in detail below.

Stephen $^{\text {ii }}$, 30s, extroverted/confident personality, self-described as troublesome within prison, took part on a GV project in a category A prison

\section{Key experiences of Good Vibrations}

Although reporting being a self-confident individual, Stephen was keen to highlight the increases in confidence he witnessed in other participants during the project. When probed a little further it became clear that he himself had found the project beneficial in terms of communication and social skills, but in different ways. For example, he explained that it was nice to be able to show his 'soft side' through the project as this was not something he felt able to do in everyday prison life. He spoke of the shock he saw on the faces of prison staff when they came to observe the project and believes they saw a different side to him:

"It showed a different side of me and it let officers see that side. Officers came up and said they didn't know that side of me existed."

Stephen went on to explain that officers began to see him as 'a person', and not just as a trouble-maker. He explained how this opened up new channels of communication for him and how he also felt this was beneficial for prison staff.

On the theme of communication, Stephen noted how the project:

“...opens people up. The music, the project, and the people working together. Everybody is listened to, everybody is heard. It's about respect." 
At the time of interview, Stephen was studying at college. This was something he had planned to do for a long time - before taking part in Good Vibrations - and he reported having taken part in lots of courses in prison. Nonetheless, he did explain appreciating the Good Vibrations as a break from more formal education and highlighted the importance of having that break to give him some thinking space away from what he described as 'boring prison education'.

Paul, 30s, extroverted/confident personality, self-described as troublesome within prison, took part on a $\mathrm{GV}$ project in a category B prison

\section{Key experiences of Good Vibrations}

Paul was also a confident individual, and reported always having been this way. Like Stephen he explained how he had seen other more introverted group members grow in confidence during the Good Vibrations project. Furthermore, he also explained how the project had an impact on his own communication and tolerance of other people. Specifically, he reported how Good Vibrations had opened his mind to viewing other people as individuals - Paul openly discussed how he had only ever mixed with five or six people in prison and made a point of avoiding sex offenders. However, through Good Vibrations he had to communicate with other people and consequently felt able to become more tolerant:

"The course was very intense. All day every day for a week. But it was extremely purposeful because of the concert and I even came to see the sex-offenders as individuals."

These greater levels of tolerance and openness, he explained, continued both in prison and on the outside.

Mark, 30s, introverted/under-confident personality, took part on a GV project in a category B prison

\section{Key experiences of Good Vibrations}

Mark was perhaps the most introverted of the participants who took part in stage three of this research, but explained that his confidence had improved greatly in recent years. He explained how well he bonded with the others in his Good Vibrations group during the project, which was unusual for him as he typically avoided 'social situations'. Mark also highlighted the confidence the course gave him in dealing with prison life in general. 
Mark commented that shy people in prison can often be reluctant to take part in any kind of course in prison and would rather 'sit and watch TV', so taking part in a Good Vibrations project in itself was a big step for him. Simply taking part has been a first step towards improving self-confidence, but this coupled with his positive group experience throughout the course appeared to begin to enhance and cement these improvements in confidence.

Mark discussed his lack of formal education, having no formal qualifications and a generally negative experience of education in his past. However, he appeared very pleased when explaining that he had recently enrolled on vocational courses outside of prison. He highlighted that in prison he only attended education classes where it was compulsory for him to do so, but was now training as a plasterer for his own benefit and actively seeking employment. It is important to note that he did not directly attribute his new found ambition and engagement with education and training to any one project and/or experience, but noted that he felt he had grown in confidence, wished to do something useful with his time, and that in the past he did not have the confidence to attend college.

Tony, 50s, introverted/under-confident personality, took part on a GV project in a category B prison

\section{Key experiences of Good Vibrations}

Tony, like Mark, explained how much he felt 'part of a group' during his Good Vibrations project. Tony discussed this at length and it seems this was particularly important for him as he generally lacked confidence and was not good at 'making friends'. He had felt apprehensive about taking part in the project, but had been encouraged by prison staff to do so, and reported feeling very pleased that he had.

Indeed, while taking part in a Good Vibrations project in itself was a big step for Tony, what is more notable is how quickly he reported finding his voice in the group and realising that he could speak out and contribute. Good Vibrations project staff specifically focus on facilitating a focus on listening and giving every group member opportunities to be heard. Tony explained how it is important to be confident in prison, and the course helped him find this confidence. 
Undoubtedly taking part in one course is unlikely to turn introverts in extroverts, but some of the men here found their voice in a Good Vibrations group and were able in some small way to continue to build upon this in the future, even outside of prison.

Tony explained that he had a good educational record and this was something he had continued in prison. However, his educational experiences had previously been solitary ones and he noted that he had never done anything like Good Vibrations before or since. Tony was in work at the time of interview.

Peter, 40s, presented as introverted/under-confident personality, took part on a GV project in a category B prison

\section{Key experiences of Good Vibrations}

Peter explained that he was a relatively confident individual but appeared very shy at interview. Nonetheless, he spoke of how the Good Vibrations he took part in was inclusive and allowed all participants to be heard.

While four of the five men mentioned how during the Good Vibrations project they felt more relaxed that they typically did within prison, it was Peter who spoke at most length about the 'humanising' experience of the project. He highlighted the freedom it made him feel, despite being in prison:

"Little things like being able to get coffee when I wanted, to smoke when I wanted, really made me feel normal."

He was keen to highlight that he had never taken part in anything even remotely like Good Vibrations before, but that his participation was an extension of his general involvement in different projects. This is reflected in Peter's reported background of taking part in educational programmes both inside and outside of prison.

\section{Discussion}

Linking directly to the findings from men in prison, the short case studies presented above demonstrate how the men had much to discuss in relation to two key themes: confidence, 
communication, and social skills; and the relationship between this and skills development, education, and training. While it is clear that the information presented above is limited and cannot provide a robust picture of the impact of taking part in project like Good Vibrations as offenders move out into the community, the findings remain important to consider. They provide a start-point for further research seeking to investigate how such projects may contribute to changes in the thinking and behaviours of offenders. It is clearly unreasonable to suggest that such projects can be directly responsible for reducing reoffending - and nor do they seek to be - but it remains important to consider how a variety of experiences can be relevant in shaping the path an offender takes towards desisting from crime.

\section{Summary of the findings with male offenders and ex-offenders}

The results here suggest that for many participants taking part in a Good Vibrations project appeared to act as a catalyst for change. The feelings of freedom and being 'normal again' engendered by the project appear to give some offenders the mental space to begin making a positive change in their lives. For those men who returned to 'normal prison life' after the project, they report taking something of the project with them and for some this seems to act as the beginning of positive change, which they are able to gradually build upon. While not all participants experienced significant individual impacts from the project likely to lead to changes in behaviour, all participants - at a minimum - experienced the project as a positive week of constructive activity.

As discussed earlier, Good Vibrations and projects like it do not seek to have a direct impact on reoffending, and nor did this research seek to measure the impact of the project in this way. However, authors have noted the potential for the arts to contribute to an offenders 
paths towards desisting from crime (Cox \& Gelsthorpe, 2008; McNeill et al., 2011) and it is important to contextualise the findings presented above in light of academic discussions of desistance. By desistance we mean understanding why and how former offenders avoid continued involvement in criminal behaviour (Maruna \& Immarigeon, 2004; Farrall \& Calverly, 2006) and as Parkes \& Bilby (2010:106) note, the arts can map an "alternative terrain to traditional concepts of rehabilitation and treatment". As highlighted by the findings of this current research, this music project was both responsive to individual need and able to engage some offenders with further education: factors that are respectively vital to engagement and related to lowered risk of future offending (Parkes \& Bilby, 2010). In addition to the above, the broader positive changes highlighted by many participants are important in understanding how the different individual experiences of offenders can contribute to their future life and actions. Elder (1985) discusses 'trajectories' and 'transitions' as central to understanding life course dynamics. He describes a trajectory as a pathway over the 'life span' that is marked by transitions. Transitions are those events, stages and processes where changes in the trajectories towards desistance occur. Carlsson (2012) argues that processes of individual change in offending and desistance from crime are complex, "often involving multiple, and context-specific processes" (2012:2). The findings presented here, for some participants, may have prompted changes that help shift the trajectories of their lives.

The interviews conducted with offenders in the community suggest that the findings from this research may extend outside of the prison environment. However, as only a small number of interviews were conducted for this stage of the research, with men who are unlikely to be representative of men in prison more generally, there is a clear need to investigate this further. 


\section{Methodological Limitations}

There are debates and potential issues with the research methodology employed. Researcher in this field contends with practical constraints in the criminal justice system and also with debates surrounding the methodologies that may be deemed 'acceptable'. Many reviews of 'effectiveness' utilise the principles of the 'Maryland Scale' (Sherman et al, 1997) to assess the scientific evidence surrounding the impact of a particular intervention (for example, see Butler, Hodgkinson, Holmes, \& Marshall 2004). Sherman et al. propose that robust evidence of causality can only be shown by studies using a robust comparison group design. However, this raises a number of issues around what 'effectiveness' means in the context of the arts in criminal justice - and this is likely to be different things to different groups - and what therefore it is appropriate to measure.

An experimental, randomised control trial design would not have been appropriate for this study, given the overall aim of this particular study which was to capture the experience of taking part in a Good vibrations project in the participants own words. It is appropriate and meaningful to track an offender's journey against their own past. Clearly it must also be acknowledged that there are potential issues with self-report data, but the inclusion of reports from prison staff and the reviewing of OASys data and adjudication reports provides a strong form of data triangulation. It is still true that participants may to some extent report what they feel the researchers want to hear, but where attitudinal and behavioural change have also been observed by prison staff this can be taken as a strong indicator that the change is real. The research aimed to capture the voices of those who had participated in the GV project and their own reports of changes, and did not seek to look at reoffending rates for a number of reasons: most arts-based programmes do not aim to directly reduce reoffending, but aim to provide participants with certain skills that may help them embark on a more positive life journey; 
and finally, binary measures of reoffending tell us nothing of the ways that individuals experience any impacts of a project.

The sample of participants at the second prison and in the community is small and therefore unlikely to be representative of every individual who has taken part in one of these projects. Furthermore, these samples were not tracked over time. It is also likely that, given their choice to take part in this research, these participants were the most motivated of the group and therefore much more likely to report positive outcomes and this should be borne in mind. Despite this, these samples are able to give us some indication of the effect that the project may have on some individuals. In addition, the participants in the community come from a range of prisons, having a range of different experiences that mirror many of the experiences of ex-offenders.

\section{Conclusions}

The results presented throughout this article suggest some common themes in the way different groups and individuals experience taking part in a Good Vibrations project. This research in particular builds upon the findings of previous evaluations of Good Vibrations and furthermore, the findings from all samples to a large extent complement and extend one another.

The findings suggest that participating in this particular project can act as a stepping-stone into further education. This is particularly interesting given that many offenders have poor educational backgrounds and are often reluctant to engage with formal education in prison, yet poor educational achievement is linked to increased risk of re-offending. Reluctance to engage in prison education may in part be due to feelings of dislike of the education system in general, but is often also due to feelings of inadequacy and fear of failure (Wilson \& 
Reuss, 2000). Here, participants reported a sense of achievement at completing the project and for some participants this may be the first time they have ever really achieved anything. Perhaps most interesting is the finding that the initial positive changes observed in some individuals seem to prompt continued positive change. Indeed, of those men whom we were able to make contact with in the community after their release from prison - most of whom had completed the Good Vibrations project at least twelve months beforehand - they were still reporting positive attitudinal changes that they suggested were prompted by their initial participation in the project. It may of course be that participants have on some level already decided to make positive changes in their behaviour, but the results from this research highlight how projects such as Good Vibrations may act as a catalyst for future behavioural change for some individuals. Participating in the project gives some people the skills, for example improved social skills, also found by Digard, et al., (2007) review of a Good Vibrations projects, to go on and make a positive change, be that learning how to cope with prison life, or going on to take part in formal education programmes. Clearly every individual is different, and changes will not happen for all, but many offenders point to a specific time they made a decision to change their behaviour, or something that prompted this decision. A sizeable amount of prison-based treatment focuses on cognitive restructuring (cf. Andrews \& Bonta, 2003), and while there is clearly a complex interplay of internal and external factors that must fit into place for offenders to make a decision to change and stick to that (LeBel, Burnett, Maruna, \& Bushway, 2008), it is possible that projects such as that reviewed here may prompt positive change for some offenders. The findings presented here are, as both Nee (2004) and Liebling and Maruna (2005) highlight is important in research in criminal justice, centred on the experience of offenders and ex-offenders. Furthermore, the findings suggest that participation in the arts may 'inspire desistance' for some offenders (McNeill et al., 2011). While the findings of this research do not suggest that participation in the arts offers a 
clear and direct path towards desistance, they do suggest that for some offenders the arts may encourage changes that set them on the complex path towards desisting from crime. This change can come directly from taking part in creative activities and also from the by-products of such activities including improvements in self-esteem and self-confidence, communication and social skills. However, this must all be viewed in the context of the value of the arts as a humanising experience. Participation in arts projects is unlikely to directly reduce offenders' likelihood of reoffending, and nor are they intended to do so, but at a basic level the findings of this research demonstrate the way such projects provide offenders with a humanising experience, too often lacking in prisons.

While the evidence presented here on the impact of arts-based project post-release is limited by sample size, the findings do suggest that, at least in prison, arts-based programmes can promote positive change for some offenders., Given the emerging evidence of the potential impact of arts based programmes, now seems the time for a serious consideration of how arts programmes can work together with traditional programmes to best target offenders' need and risk.

With reference to the discussion within the methodology of how evidence of 'effectiveness' of interventions with offenders is best sought, we argue that it is entirely appropriate and meaningful to track an offenders journey against their own past. Furthermore, that to measure the impact of arts-based programmes on reoffending rates is clearly unreasonable. Such programmes do not seek to directly reduce reoffending, but may aim to contribute to changes in the thinking and behaviours of offenders and it remains important to consider how a variety of experiences can be relevant in shaping the path an offender takes towards desisting from crime. This research has begun to map this journey in relation to one particular artsbased project. 


\section{References}

Albertson, K. (2015). Creativity, Self-exploration and Change: Creative Arts-based Activities' Contribution to Desistance Narratives. The Howard Journal of Criminal Justice, 54, 277-291.

Allen, K., Shaw, P. and Hall, J. (2004). The Art of Rehabilitation: Attitudes to Offenders' Involvement in the Arts. London: Esmée Fairburn Foundation.

Andrews, D. A. and Bonta, J. (2003). The psychology of criminal conduct, 3rd ed. Cincinnati, $\mathrm{OH}$ : Anderson.

Armstrong, D., Gosling, A., Weinman, J., and Marteau, T. (1997). The place of inter-rater reliability in qualitative research: an empirical study. Sociology, 31(3), 597-606.

Bilby, C., Caulfield, L.S., and Ridley, L. (2013). Re-Imagining Futures: Exploring arts interventions and the process of desistance. Final grant report for the Arts Alliance.

Blacker, J., Watson, A. and Beech, A. (2008). A combined drama-based and CBT approach to working with self-reported anger aggression. Criminal Behaviour and Mental Health, 18, 129-137.

Butler, G., Hodgkinson, J., Holmes, E., and Marshall, S. (2004). Evidence Based Approaches to Reducing Gang Violence. Government Office West Midlands and Home Office Research Team.

Carlsson, C. (2012). Using turning points to understand processes of change in offending, British Journal of Criminology, 52 (1), 1-16.

Caulfield, L., Wilson, D., and Wilkinson, D.J. (2009). Continuing Positive Change in Prison and the Community. Grant report to Good Vibrations Report.

Caulfield, L.S. and Hill, J. (2014). Criminological research for beginners: a student's guide. London: Routledge, UK. 
Cox, A. and Gelsthorpe, L. (2008). Beats and bars - Music in prisons: An evaluation. The Irene Taylor Trust.

Cox, A. and Gelsthorpe, L. (2012). 'Creative Encounters: Whatever Happened to the Arts in Prisons?' in L. K. Cheliotis (ed) The Arts of Imprisonment, Farnham: Ashgate, 257276.

Digard, L., Grafin von Sponeck, A. and Liebling, A. (2007). All Together Now: The therapeutic potential of a prison-based music programme. The Prison Service Journal, $170,3-14$.

Eastburn, C. (2003). Gongs behind bars: Evaluation report of the Good Vibrations Gamelan in Prisons pilot project 2003. Wellingore: The Firebird Trust.

Elder, H. (1985). Methods of life course research: Qualitative and quantitative approaches (5-27), Thousand Oaks, CA: Sage.

Farrall, S. and Calverley, A. (2006). Understanding desistance from crime. Berkshire: Open University Press.

Henley, J. (2009). Learning Gamelan: A teacher's experience. National Association of Music Educators magazine, 2010.

HM Prison Service (2015). What we do. Retrieved $23^{\text {rd }}$ June 2015 from https://www.gov.uk/government/organisations/hm-prison-service

Jupp, V., Davies, P. and Francis, P. (2006). Doing Criminological Research. London: Sage.LeBel, T.P, Burnett, R., Maruna, S., and Bushway, S. (2008). The 'Chicken and Egg' of Subjective and Social Factors in Desistance from Crime. European Journal of Criminology , 5, 131-159.

LeBel, T. P., Burnett, R., Maruna, S. and Bushway, S. (2008). ' The 'chicken and egg' of subjective and social factors in desistance from crime', European Journal of Criminology, 5, 131- 159. 
Liebling, A. and Maruna, S. (eds) (2005). The Effects of Imprisonment, Cullompton, Devon: Willan Publishing.

Maruna, S. and Immarigeon, R. (2004). After Crime and Punishment. Devon: Willan Publishing.

McNeill, F., Anderson, K., Colvin, S., Overy, K., Sparks, R. and Tett, L. (2011). Inspiring Desistance? Arts projects and 'what works?'. Available: http://blogs.iriss.org.uk/discoveringdesistance/files/2011/09/McNeill-et-al.-2011Inspiring-Desistance.pdf

Miles, A. and Clarke, R. (2006). The arts in criminal justice: A study of research feasibility. University of Manchester: Centre for Research on socio cultural change.

Ministry of Justice (2008). Third sector strategy: Improving policies and securing better public services through effective partnerships, 2008-2011. London: Ministry of Justice.

Ministry of Justice (2010). Breaking the Cycle: Effective punishment, rehabilitation and sentencing of offenders, Ministry of Justice: London. Available at http://webarchive.nationalarchives.gov.uk/20120119200607/http:/www.justice.gov.uk /consultations/docs/breaking-the-cycle.pdf

Ministry of Justice (2013). Transforming rehabilitation: a summary of evidence on reducing re-offending' Ministry of Justice: London. Available at https://www.gov.uk/government/publications/transforming-rehabilitation-a-summaryof-evidence-on-reducing-reoffending

National Offender Management Service (2012). NOMS Commissioning Intentions for 201314: Negotiation Document, NOMS: London. Available at http://www.justice.gov.uk/about/noms/commissioning 
Nee, C. (2004). The offender's perspective on crime: Methods and principles in data collection. In A. Needs and G. Towl (Eds.), Applying psychology to forensic practice. Oxford: BPS Blackwell.

Owers, A. (2008). Prisons and the prevention of reoffending. Centre for Criminal Justice Studies Frank Dawtry Memorial Lecture, University of Leeds.

Parkes, R. and Bilby, C. (2010). The Courage to Create: The Role of Artistic and Spiritual Activities on Prisons. The Howard Journal of Criminal Justice, 49, 97-110

Prison Reform Trust (2013). Bromley Briefing prison factfile. London: Prison Reform Trust. Reuss, A. (1999). Prison(er) Education. The Howard Journal of Criminal Justice, 38,113127.

Scottish Prison Service (2012). Freedom of information request obtained by the Scottish Conservatives. Available at: http://www.scottishconservatives.com/2012/12/literacy$\underline{\text { crisis-in-scotlands-jails/ }}$

Sherman, L., Gottfredson, D., MacKenzie, D., Eck, J., Reuter, P. and Bushway, S. (1997). Preventing Crime: What Works, What Doesn't, What's Promising. Washington: US Department of Justice

Wilson, D. and Logan, M. (2006). Breaking Down Walls - The Good Vibrations Project in Prison. Birmingham: Centre for Criminal Justice Policy and Research.

Wilson, D. and Reuss, A. (2000). Prison(er) education: stories of change and transformation. Water Side Press: London.

Wilson, D., Caulfield, L.S., and Atherton, S. (2009). Good Vibrations: The long-term impact of a prison based music project, The Prison Service Journal, 182, 27-32. 
Table 1 - The Research Process 


\footnotetext{
${ }^{\mathrm{i}}$ OASys is a need and risk assessment used throughout the prison and probation service in England and Wales
}

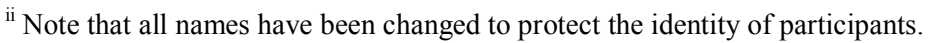

iii Note on Stage Two: Fourteen participants took part in the Good Vibrations project most recent to the research visits. The research team hoped to interview as many of these participants as possible as well as speak with wing staff. While the researchers were able to speak to the majority of new participants at the prison involved in Stage One of the research, only two participants were able and willing to be interviewed at the second prison. This was due to organisational issues within the prison. Both of the participants who were interviewed were adult males, aged 25 and 35 and were due for release within the next six months. Of note is that two of the 'new' project participants had taken part in a project previously and were included in Stage One of this research. Four of the new Good Vibrations participants were interviewed. Two men could not take part in the research due to their prison work commitments. Interestingly, only the two men with medium risk scores had a history of adjudications at the prison, both having been found guilty of three adjudications each during 2006 and 2007. Receiving this number of adjudications in a less than twelve month period is relatively unusual and suggests that these two men had a history of trouble-making within the prison. Indeed, during interview both of these participants were open about their history of bad behaviour, and their tendency towards anger and getting involved in conflict situations.

iv Note on Stage Three: At the time of interview, four of these participants had taken part in a Good Vibrations project between thirteen and eighteen months ago. One of the men had taken part in the project only seven months ago. Despite falling outside of our definition of 'long-term' it was clearly important and relevant to include this participant as his experiences of moving from prison into the community were the main focus of this stage of the research. As far as we can ascertain, all of this group were medium or high-risk. The men interviewed presented a range of different personality types and experiences of prison life. Two men presented as particularly confident and their brief description of their experiences of prison life adds weight to this. Both of these men discussed how they had at times been a source of trouble for prison staff and presented what can be best described as a 'hard-man' persona within prison. Of the other three men, two openly discussed their general levels of introversion and shyness while one man suggested he was relatively confident but did not present as confident throughout the interview. 